\author{
Holly A. Muir MD FRCPC, \\ Desmond Writer MB CHB FRCPC, * \\ Joanne Douglas MD FRCPC, ${ }^{\dagger}$ \\ Sally Weeks MB BS FRCA, ${ }^{\ddagger}$ \\ David Gambling MB BS FRCPC, ${ }^{\dagger}$ \\ Alison Macarthur MD FRCPC $\ddagger$
}

\title{
Double-blind comparison of epidural ropivacaine $0.25 \%$ and bupivacaine $0.25 \%$, for the relief of childbirth pain
}

Purpose: To evaluate the efficacy of ropivacaine $0.25 \%$ when administered epidurally for relief of labour pain and to compare it with bupivacaine $0.25 \%$.

Methods: In a multicentre investigation, $60 \mathrm{ASA}$ I and II labouring women were randomized in a double-blind fashion to receive either bupivacaine $0.25 \%$ or ropivacaine $0.25 \%$ administered epidurally by intermittent top-up for labour analgesia. Using a standardized technique, epidural analgesia was initiated after the woman received 10-15 $\mathrm{ml} \cdot \mathrm{kg}$ ' crystalloid solution. Maternal blood pressure, heart rate, analgesia sensory level, degree of motor block and visual analogue pain scores were measured by the research nurse prior to, and at regular intervals, following the administration of analgesia. Total dose of local anaesthetic administered, duration of labour, mode of delivery, and maternal and fetal/neonatal side effects were noted. The fetus/neonate was assessed by the research nurse using the fetal heart rate tracing. Apgar scores at delivery and neonatal neurobehavioural assessments at 2 and $24 \mathrm{hr}$ postnatally. Maternal and investigators' satisfaction with the analgesia achieved was assessed after delivery.

Results: No differences were found between the two agents in any of the variables studied.

Conclusion: Ropivacaine $0.25 \%$, when administered epidurally by intermittent top-ups for labour analgesia, was equally efficacious as bupivacaine $0.25 \%$.

Objectif : Évaluer l'efficacité de la ropivacaïne épidurale $0.25 \%$ administrée pour soulager la douleur du travail et la comparer avec la bupivacaine $0,25 \%$.

Méthodes : Au cours d'une investigation multicentrique, 60 parturientes ASA I et II en travail ont été réparties aléatoirement pour recevoir en double aveugle soit de la bupivacainne $0,25 \%$ soit de la ropivacaine $0,25 \%$ administrées en doses intermittentes épidurales pour le soulagement de la douleur du travail. Avec une technique standardisée, l'analgésie épidurale a été induite après l'administration de $10-15 \mathrm{ml} / \mathrm{kg}^{-1}$ d'une solution de cristallö̈de. La pression artérielle et la fréquence cardiaque matemelles, le niveau du bloc sensitif et moteur et le score de la douleur sur une échelle visuelle analogique ont été enregistrés par une infirmière de recherche avant et à intervalles réguliers après l'administration de l'anesthésie. La dose totale administrée d'anesthésique local, la durée du travail, le mode d'accouchement et les effets matemels et foetaux ont aussi été enregistrés. Le foetus et, par la suite, le nouveau-né a été évalué par l'infirmière de recherche avec le tracé du coeur foetal, le score d'Apgar à la naissance et des évaluations neurocomportementales à deux et 24 heures après la naissance. Le degré de satisfaction de la mère et des investigateurs relativement à l'analgésie a été évalué après l'accouchement.

Résultats : Aucune différence entre les deux agents n'a été notée en ce qui conceme les variables étudiées. Conclusion : La ropivacaine $0.25 \%$ en administration épidurale à doses intermittentes pour l'analgésie du travail a été aussi efficace que la bupivacaïne $0,25 \%$.

*From the Department of Anaesthesia, IWK-Grace Health Centre, Dalhousie University, Halifax, NS, Canada. 'Department of

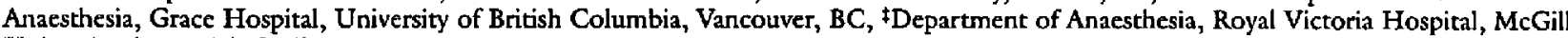
University, Montréal, Québec.

Address correspondence to: Dr. Holly A. Muir, IWK-Grace Health Cencre, 5980 University Avenue, Halifax, Nova Scotia, Canada B3T 3G9.

This study was supported by a grant from ASTRA Pain Control AB.

Accepted for publication March 1, 1997. 
$\mathrm{R}$ OPIVACAINE is an amide-type local anaesthetic structurally related to bupivacaine and mepivacaine but, unlike these two agents, prepared as an isomer, (S)-(-)-1Propyl-2',6'-pipecoloxylidide hydrochloride monohydrate. In early animal and human studies, ropivacaine demonstrated local anaestheric properties, with a potency and duration of action slightly less than that of bupivacaine. In addition, the depth and duration of motor block was less with ropivacaine., ${ }^{1,2}$

In obstetrical anaesthesia, bupivacaine remains the preferred local anaesthetic for the relief of labour pain, although the occurrence of adverse effects, including cardiotoxicity and cardiac arrest, resulted in withdrawal of the $0.75 \%$ concentration. ${ }^{3-5}$ Comparison of the pharmacokinetic properties of ropivacaine and bupivacaine shows a shorter elimination half-life for ropivacaine after intravenous administration. ${ }^{6}$ This may indicate a greater margin of safety for this agent. In toxicity studies using human volunteers, ropivacaine, when administered by intravenous infusion, proved less toxic than bupivacaine, with respect to signs and symptoms of mild central nervous system and cardiovascular toxicity. 7,8

The purpose of this study was to evaluate the efficacy of ropivacaine $0.25 \%$ when administered epidurally for the relief of labour pain, and to compare it with bupivacaine $0.25 \%$ We made observations on the side effects for both mothers and fetuses/neonates.

\section{Materials and methods}

Sixty ASA I or II primiparous or multiparous women in active labour, were to be recruited into this multicentre prospective randomized double-blind study. Three centres participated in the study with 20 cases allocated to each centre. The patients were randomized in blocks of four at each centre with an equal probability of receiving either of the two treatments. Stratification for each centre with regard to primiparae and multiparae was made. The research and ethics committees of the individual centres approved the study protocol. All participants gave informed written consent to enter the trial before receiving epidural analgesia for relief of their labour pain.

Parturients between the ages of 16 and $40 \mathrm{yr}$, with a height $\geq 145 \mathrm{~cm}$, weight $\leq 110 \mathrm{~kg}$, and body mass index $\leq 30$, and having a full-term singleton fetus, were eligible for inclusion in the study. Women with a history of allergy or sensitivity to amide local anaesthetics, or those who had received previous analgesia other than a single dose of meperidine (maximum $125 \mathrm{mg}$ ) were excluded.

Subjects received a preload of crystalloid solution, $10-15 \mathrm{ml} \cdot \mathrm{kg}^{-1}$ (normal saline or Ringer's lactate), imme- diately before epidural analgesia. With each patient in the left lateral or sitting position, the epidural space at the $\mathrm{L}_{2-3}$ or $\mathrm{L}_{3-4}$ interspace was identified, using a 16-18 gauge Tuohy needle and loss of resistance with saline $(\leq 4 \mathrm{ml})$ and air, and a multi orifice epidural catheter 3-5 $\mathrm{cm}$ was inserted into the epidural space.

A test dose of $5 \mathrm{ml}$ study drug (ropivacaine $0.25 \%$, or bupivacaine $0.25 \%$, in a coded ampule) was administered through the epidural catheter. Two minutes later, if no signs of intravascular or intrathecal administration occurred, a second $5 \mathrm{ml}$ dose of the same drug was given. Subjects received an additional $5 \mathrm{ml}$ of study drug after $10 \mathrm{~min}$, if the main dose of $10 \mathrm{ml}$ failed to provide satisfactory analgesia. Intermittent top-up doses of $10 \mathrm{ml}$ study drug were given when participants requested additional pain relief (to a maximum of eight top-ups, or $\mathbf{1 7 5} \mathrm{mg}$ of drug in three hours).

Maternal blood pressure, heart rate and fetal heart rate were recorded before initiation of the block, after administration of each top-up dose, and at regular intervals thereafter. Assessments of sensory (pinprick) and motor block (modified Bromage score - Table 1), were performed bilaterally every $15 \mathrm{~min}$ until delivery, then every $30 \mathrm{~min}$ until return of normal sensation and motor function. Investigators recorded the time to onset, and final regression of analgesia at $T_{12}$, as well as maximum upper and lower segmental spread, and onset and regression of motor block at the hip, knee, and ankle.

After initiation of the block, parturients assessed the onset of pain relief using a verbal scale after each contraction, until they attained grade 3 or grade 4 relief (Table II). A visual analog scale of $0-100 \mathrm{~mm}$ (VAS) ${ }^{9}$ was used to determine baseline pain scores prior to initiation of the block, and at the first contraction after each 15 min interval, until delivery. After delivery, patients and investigators judged the quality of analgesia obtained, with the use of a verbal scale.

TABLE I Modified Bromage score

\begin{tabular}{ll}
\hline Motor Block Modified Bromage Scale \\
\hline 0 & No motor block \\
1 & Inability to raise extended legs (just able to move knees) \\
2 & Inability to flex knees (able to move feet only) \\
3 & Inability to flex ankle joints (unable to move feet or knees) \\
\hline
\end{tabular}

TABLE II Verbal pain scalc

\begin{tabular}{ll}
\hline Onset of Pain Relief Verbal Scale \\
\hline 1 & No pain relief \\
2 & Little pain relief \\
3 & A lot of pain relief \\
4 & Complete pain relief \\
\hline
\end{tabular}


TABLE III Patient demographics

\begin{tabular}{lll}
\hline Variable & Ropivacaine & Bupivacaine \\
\hline & $\mathrm{n}=34$ & $\mathrm{n}=26$ \\
Age (yr) & $28 \pm 5$ & $28 \pm 6$ \\
Height (cm) & $163 \pm 7$ & $165 \pm 7$ \\
Weight (kg) & $75 \pm 11$ & $78 \pm 12$ \\
ASA Status I & 31 & 23 \\
ASA Status II & 3 & 3 \\
Parity-primigravida & 18 & 13 \\
Multipara & 16 & 13 \\
\hline
\end{tabular}

Mean $\pm S D$

The time to completion of first stage labour (full dilatation with urge to push), and second stage (delivery), and the mode of delivery were recorded. Neonatal evaluation included Apgar scores at one and five minutes, and Neurologic Adaptive Capacity Scores (NACS) at 2 and $24 \mathrm{hr}$ after delivery. ${ }^{10}$ All adverse events observed or reported in patients, fetuses or neonates were recorded.

\section{Statistical analysis}

The sample size for the study was calculated with the aim of showing a difference between treatments in the time to first request for a top-up dose. In a similar type study the standard deviation of the duration of painfree contractions was about $44 \mathrm{~min} .{ }^{11}$ If, when comparing the two treatments, the difference is at least 40 min, and if 30 patients per group are included, the power of detecting a difference between treatments is about $90 \%$. This is based on a two-tailed t test performed at the 0.05 significance level, assuming equal variance in the groups and normally distributed data.

The data were analysed using standard statistical methods. Two-sided $95 \%$ confidence intervals and tests based on a full ANOVA model with fixed factor effects for centre, parity and treatment were used for the variables time-to-onset of pain relief, duration of analgesia between top-ups, and mean VAS. Interaction factors were included in the model but removed when found to be non-significant. Quality of analgesia and NACS and were analysed using stratified Wilcoxon rank sum test. All tests were two-tailed and $P$ values $<0.05$ were regarded as statistically significant.
TABLE IV Delivery outcome

\begin{tabular}{|c|c|c|}
\hline & Ropipacaine $n=34$ & Bupivacaine $n=26$ \\
\hline $\begin{array}{l}\text { Time from first VAS to } \\
\text { delivery. Median (range) }\end{array}$ & $6.6 \mathrm{hr}(0.6-12.5 \mathrm{hr})$ & $5.8 \mathrm{hr}(1.3-13.6 \mathrm{hr})$ \\
\hline \multicolumn{3}{|l|}{ Mode of Delivery } \\
\hline Spontaneous vertex & $\mathrm{n}=18(53 \%)$ & $n=16(61 \%)$ \\
\hline Vacuum extraction & $\mathrm{n}=5(15 \%)$ & $n=2(8 \%)$ \\
\hline Forceps & $\mathrm{n}=7(20 \%)$ & $\mathrm{n}=7(27 \%)$ \\
\hline Caesarean section & $\mathrm{n}=4(12 \%)$ & $\mathrm{n}=1(4 \%)$ \\
\hline
\end{tabular}

\section{Results}

Sixty-five subjects were enrolled, but five were excluded from analysis, due to technical failures. Technical failure was defined as total failure to achieve evidence of an epidural block after administration of the main dose of study drug, as assessed by the investigator and considered to be due to an incorrectly placed injection. Therefore, 60 subjects underwent efficacy and safety analysis - 34 in the ropivacaine group, and 26 bupivacaine. The groups were similar in demographic attributes (Table III).

All patients received the main dose of $10 \mathrm{ml}(25 \mathrm{mg})$ of ropivacaine $0.25 \%$ or bupivacaine $0.25 \%$. Eleven patients in the ropivacaine group, and nine in the bupivacaine group, required an additional $5 \mathrm{ml}$ of study drug to establish analgesia. The mean total volume of study drug administered was similar in the two groups. Median duration of treatment was four hours for ropivacaine and two hours for bupivacaine. Time to delivery from entry into the study were not different between the two groups (Table IV). Mode of delivery was recorded but no provision was made in the protocol to control for factors affecting mode of delivery such as variations in obstetric practise (Table IV). Ropivacaine showed no differences compared with bupivacaine in time-to-onset of pain relief, duration of analgesia between top-ups, mean VAS scores (Figure 1), and quality of analgesia, as judged by investigators and patients (Table V). The extent and duration of sensory analgesia was similar with the two agents. The median upper segmental spread was $T_{8}$ for ropivacaine and bupivacaine, and median lower seg-

TABLE V Quality of analgesia with ropivacaine and bupivacaine, as assessed by patients and investigators

\begin{tabular}{lllll}
\hline Quality of analgesia & $\begin{array}{l}\text { Ropivacaine } \\
\text { (Patient) }\end{array}$ & $\begin{array}{l}\text { Bupivacaine } \\
\text { (Patient) }\end{array}$ & $\begin{array}{l}\text { Ropivacaine } \\
\text { (Investigator) }\end{array}$ & $\begin{array}{l}\text { Bupivacaine } \\
\text { (Investigator) }\end{array}$ \\
\hline Exccllent & 28 & 18 & 28 & 19 \\
Good & 5 & 8 & 11 & 7 \\
Fair & 1 & 0 & 2 & 0 \\
Poor & 0 & 0 & 0 & 0 \\
\hline
\end{tabular}

No significant differences 


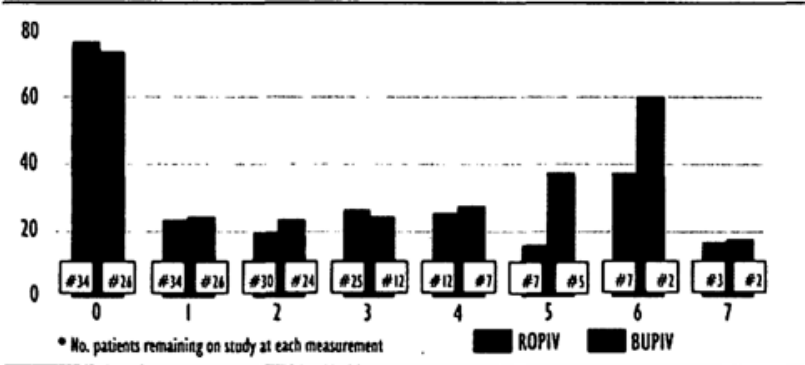

FIGURE 1 Mean VAS score prior to initiation of analgesia (0) and 15 minutes after each administration of study drug (1-7)

mental spread S4 for ropivacaine, and S3 for bupivacaine. Median time-to recovery of normal sensation in the ropivacaine and bupivacaine groups was 2.5 and $3.3 \mathrm{hr}$ respectively.

The number of parturients without motor block did not differ between the two groups. Twenty-seven subjects $(79 \%)$ in the ropivacaine group, and $15(58 \%)$, in the bupivacaine group, had no motor block $(P=0.07)$ (Table VI). One subject in the ropivacaine group had unilateral grade 3 motor block with complete absence of motor block on the opposite side. Despite this unusual pattern, she had bilaterally symmetrical sensory block. The incidence of adverse events, side-effects, and their severity was similar between the two groups. In the postpartum period, mothers sporadically reported a variety of adverse symptoms including numbness, backache, and urinary symptoms, but none frequent enough to establish a pattern in either group.

Abnormalities in fetal heart rate (FHR) occurred in both groups. Severe fetal bradycardia was noted in two subjects in the ropivacaine group. In one woman, this occurred during second stage labour, and resulted in immediate vacuum delivery, without neonatal sequelae. In the other patient, repeated episodes of fetal bradycardia occurred throughout labour, but responded to positional changes and oxygen administration. At delivery, this neonate was noted to have low birth weight, the suspected aetiology being poor placental perfusion. Thirty one of 34 neonates (91\%) in the ropivacaine group, and 24 of 26 neonates (92\%) in the bupivacaine group, had Apgar scores $\geq 7$ at five minutes. No differences were found in NACS scores at two hours between the groups. At $24 \mathrm{hr}$, three babies in the ropivacaine group, and one in the bupivacaine group had NACS scores $<35$. The most common adverse events noted in neonates were hyperbilirubinaemia (ropivacaine $6 \%$; bupivacaine $4 \%$ ), and fever (ropivacaine $0 \%$, and bupivacaine $8 \%$ ). The incidence of these events appears similar to that seen in the normal neonatal population
TABLE VI Extent of motor block

\begin{tabular}{lcc}
\hline Extent of Motor Block & $\begin{array}{c}\text { Ropivacaine } \\
(n=34)\end{array}$ & $\begin{array}{c}\text { Bupipacaine } \\
(n=26)\end{array}$ \\
\hline No motor block & 27 & 15 \\
Bromage degree 1 & 5 & 9 \\
Bromage degree 2 & 1 & 2 \\
Bromage degree 3 & 1 & 0 \\
\hline
\end{tabular}

No significant differences

\section{Discussion}

Ropivacaine is a new local anaesthetic with similar physicochemical properties to bupivacaine. Although its pharmacokinetic profile after intravenous injection shows a faster elimination half-life $\left(t_{1 / 2} B\right)$ than bupivacaine, early studies demonstrated no difference between the two agents after epidural administration. ${ }^{6}$

In this multicentre study, ropivacaine $0.25 \%$ proved equivalent to bupivacaine $0.25 \%$ in time-to-onset of pain relief, duration of action, quality of analgesia, and extent and duration of sensory block. The presence of motor block was assessed during the study period, although the study was not designed to detect a difference in onset, duration or degree of block between parturients. The number of subjects who experienced motor block differed numerically between ropivacaine and bupivacaine $21 \%$ vs $42 \%$, but this difference was not statistically significant. However, this finding is similar to observations made in animal and preclinical studies, in which epidural administration of ropivacaine or bupivacaine, in equal concentration, produced less motor block after ropivacaine. ${ }^{2,12,13}$ In their comparative labour study of ropivacaine $0.25 \%$, and bupivacaine $0.25 \%$, Eddleston et al. ${ }^{14}$ also found a higher proportion of patients with no motor block in the ropivacaine group (however likewise this difference did not reach statistical significance). Although also not statistically significant, they suggested the more frequent occurrence of spontaneous vaginal delivery in their ropivacaine group may be linked to this finding. We did not observe this difference in delivery outcome between groups. The protocol for this and Eddleston's study was designed to assess efficacy, and therefore the many confounding variables affecting delivery outcome were not controlled or monitored. Data from these studies may not accurately predict the effect of the agent on delivery outcome. The whole issue of the affect of epidural analgesia on labour outcome remains controversial. One woman in the ropivacaine group developed a higher grade of 
motor block (grade 3) than any in the bupivacaine group. This occurred unilaterally, despite adequate bilateral sensory block. We believe this probably represented asymmetrical catheter placement within the epidural space.

In 1985, Morishima et al. ${ }^{15}$ suggested that the central nervous system (CNS) and cardiovascular toxicity of bupivacaine may be enhanced during pregnancy. Signs of CNS and cardiovascular toxicity appeared at a lower bupivacaine dose in the pregnant ewe, than in the non-pregnant animal. A later study using ropivacaine failed to show a difference in toxicity between pregnant and non-pregnant ewes. ${ }^{16}$ Recently, Santos $e t$ al. ${ }^{17}$ compared the toxicity of bupivacaine and ropivacaine in a double-blind study of pregnant versus nonpregnant ewes. They were unable to demonstrate a difference in toxicity between the pregnant and nonpregnant states but confirmed an increased margin of safety with ropivacaine. Larger doses of ropivacaine, than of bupivacaine, were required to produce toxic manifestations. Cardiovascular responses were monitored by clinical means in this study, and continuous maternal ECG monitoring, or more invasive methods of assessment were not undertaken. However, there were no differences in the incidences of hypotension, occurrence of maternal heart rate changes following the institution of block, or FHR abnormalities between groups. Although some investigators have described the occurrence of FHR decelerations following bupivacaine ${ }^{18,19}$ others have not observed this effect. ${ }^{20}$ The determination of whether ropivacaine possesses advantages over bupivacaine in this respect requires a larger-scale prospective, randomized study.

Of paramount concern in evaluating an agent for use in labouring women is the placental transfer of the agent and its effects on the fetus and neonate. Initial pharmacokinetic studies suggested reduced maternal protein binding of ropivacaine, compared with bupivacaine, which led to a greater concentration of free drug in the serum. ${ }^{12}$ If this unbound fraction of agent were to cross the placenta it might affect fetal wellbeing. In light of this finding, Datta $e t$ al. ${ }^{21}$ compared ropivacaine and bupivacaine (in an epidural dose of $150 \mathrm{mg}$ ) in a randomized double-blind study of women undergoing caesarean section. They measured the free (unbound) concentration of drug in maternal and fetal serum, and $C_{\max }$ and $t_{1 / 2} B$ in the mother. The Cmax was found to be similar for both drugs but the $t_{1 / 2} ß$ was shorter with ropivacaine. The free plasma concentrations of ropivacaine in both maternal and fetal blood at delivery were twice those of bupivacaine, but the ratio of umbilical vein to maternal vein concentration for unbound drug proved similar for both agents.
Neonates were evaluated using Apgar scores at one and five minutes, cord blood gases and neurobehavioural assessments. All the neonates in both groups had Apgar scores >7, normal blood gases and normal neurobehavioural assessments. Our neonatal findings confirmed those of Datta's group.

In summary, ropivacaine $0.25 \%$, was similar in efficacy for labour analgesia to bupivacaine $0.25 \%$ when administered by intermittent top-up. Ropivacaine is similar to bupivacaine, with regard to maternal, fetal and neonatal effects. Ropivacaine may offer some advantage over bupivacaine, especially with respect to the incidence of motor block, which is a troublesome side-effect of epidural analgesia. Further studies of epidural analgesia in the obstetric population, using lower ropivacaine concentrations in combination with epidural opioids are required to assess the potential benefits of this trend to reduced motor block.

\section{References}

1 Feldman HS, Covino BG. Comparative motor-blocking effects of bupivacaine and ropivacaine, a new amino amide local anesthetic, in the rat and dog. Anesth Analg 1988; 67: 1047-52.

2 Brockway MS, Bannister J, McClure JH, McKeown D, Wildsmith $J A W$. Comparison of extradural ropivacaine and bupivacaine. Br J Anaesth 1991; 66: 31-7.

3 Albright $G A$. Cardiac arrest following regional anesthesia with etidocaine or bupivacaine (Editorial). Anesthesiology 1979; 51: 285-7.

4 Albright $G A$. Epinephrine should be used with the therapeutic dose of bupivacaine in obstetrics (Letter). Anesthesiology 1984; 61: 217-9.

5 Clarkson CW, Hondeghem LM. Mechanism for bupivacaine depression of cardiac conduction: fast block of sodium channels during the action potential with slow recovery from block during diastole. Anesthesiology 1985; 62: 396-405.

6 Arthur GR, Feldman HS, Covino BG. Comparative pharmacokinetics of bupivacaine and ropivacaine, a new amide local anesthetic. Anesth Analg 1988; 67: 1053-8.

7 Katz JA, Bridenbaugh PO, Knarr DC, Helton SH, Denson $D D$. Pharmacodynamics and pharmacokinetics of epidural ropivacaine in humans. Anesth Analg 1990; 70: 16-21.

8 Scott DB, Lee $A$, Fagan D, Bowler GMR, Bloomfield $P$, Lundh $R$. Acute toxicity of ropivacaine compared with that of bupivacaine. Anesth Analg 1989; 69: 563-9.

9 Huskisson EC. Measurement of pain. Lancet 1974; 2 ; 1127-31.

10 Amiel-Tisen C, Barrier G, Shnider SM, Levinson G, Hughes SC, Stefani SJ. A new neurologic and adaptive 
capacity scoring system for evaluating obstetric medications in full-term newborns. Anesthesiology 1982; 56: 340-50.

11. Littlewood DG, Scott DB, Wilson J, Covino BG. Comparative anaesthesia properties of various local anaesthetic agents in extradural block for labour. $\mathrm{Br} \mathrm{J}$ Anaesth 1977; 49: 75-9.

12 Morrison LMM, Emanuelsson BM, McClure JH, et al. Efficacy and kinetics of extradural ropivacaine: comparison with bupivacaine. $\mathrm{Br} J$ Anaesth 1994; 72: 164-9.

13 Wolff AP, Hasselström L, Kerkkamp HE, Gielen MJ. Extradural ropivacaine and bupivacaine in hip surgery. Br. J Anaesth 1995; 74: 458-60.

14 Eddelston JM, Holland J, Griffin RP, Corbett $A$, Horsman EL, Reynolds F. A double-blind comparison of $0.25 \%$ ropivacaine and $0.25 \%$ bupivacaine for extradural analgesia in labour. Br J Anaesth 1996; 76: 66-71.

15 Morishima HO, Pedersen H, Finster $M$, et al. Bupivacaine toxicity in pregnant and nonpregnant ewes. Anesthesiology 1985; 63: 134-9.

16 Santos $A C$, Arthur GR, Pedersen H, Morishima $H O$, Finster $M$, Covino BG. Systemic toxicity of ropivacaine during ovine pregnancy. Anesthesiology 1991; 75: $137-41$

17 Santos $A C$, Arthur GR, Wlody D, De Armas $P$, Morishima HO, Finster $M$. Comparative systemic toxicity of ropivacaine and bupivacaine in nonpregnant and pregnant ewes. Anesthesiology 1995; 82: 734-40.

18 Abboud TK, Khoo SS, Miller F, Dean T, Henriksen EH. Maternal, fetal, and neonatal responses after epidural anesthesia with bupivacaine, 2 -chloroprocaine, or lidocaine. Anesth Analg 1982; 61: 638-44.

19 Steiger RM, Nageotte MP. Effect of uterine contractility and maternal hypotension on prolonged decelerations after bupivacaine epidural anesthesia. Am J Obstet Gynecol 1990; 163: 808-12.

20 Pello LC, Rosevear SK, Dawes GS, Moulden M, Redman $C W G$. Computerized fetal heart rate analysis in labor. Obstet Gynecol 1991; 78: 602-10.

21 Datta S, Camann W, Bader $A$, vanderBurgh $L$. Clinical effects and maternal and fetal plasma concentrations of epidural ropivacaine versus bupivacaine for cesarean section. Anesthesiology 1995; 82: 1346-52. 